\title{
Nuevas técnicas constructivas para el Ecuador
}

\section{New Construction Techniques for Ecuador}

\section{PABLO CAIZA SÁNCHEZ}

Universidad de las Fuerzas Armadas ESPE, Av. General Rumiñahui s/n y Ambato, Sangolquí - Ecuador

\section{INTRODUCCIÓN}

Obtuve una beca Fulbright en el año 2007, lo que constituyó el impulso inicial para finalmente alcanzar en el año 2012 el grado de PhD en Ingeniería Civil de la Universidad de Illinois en Urbana-Champaign. Fueron años de retos cumplidos que me sumergieron en un mundo de avance tecnológico. Una de las estrategias para no ahogarme, para superar mis limitaciones, enfrentar y dominar las innumerables exigencias de mis estudios, fue abrir mi mente a los cambios. En efecto, era evidente que mi cerebro filtraba la información que recibía y sólo aceptaba la que se acomodaba a patrones establecidos por los años de experiencia y vida. Pero los nuevos conocimientos eran tan diferentes, que necesité generar también nuevos patrones de aprendizaje, o fracasar en mis estudios y mis sueños.

El sismo de 16 de abril de 2016, también ha puesto a los ingenieros estructurales ecuatorianos frente a la realidad de que las formas tradicionales de construcción producen daño excesivo y que por tanto hay necesidad de nuevas técnicas que permitan controlar este daño de mejor forma. La Figura 1 muestra daño en mamposterías por fuerzas excesivas y también en elementos no estructurales por aceleraciones muy altas que producen su caída.
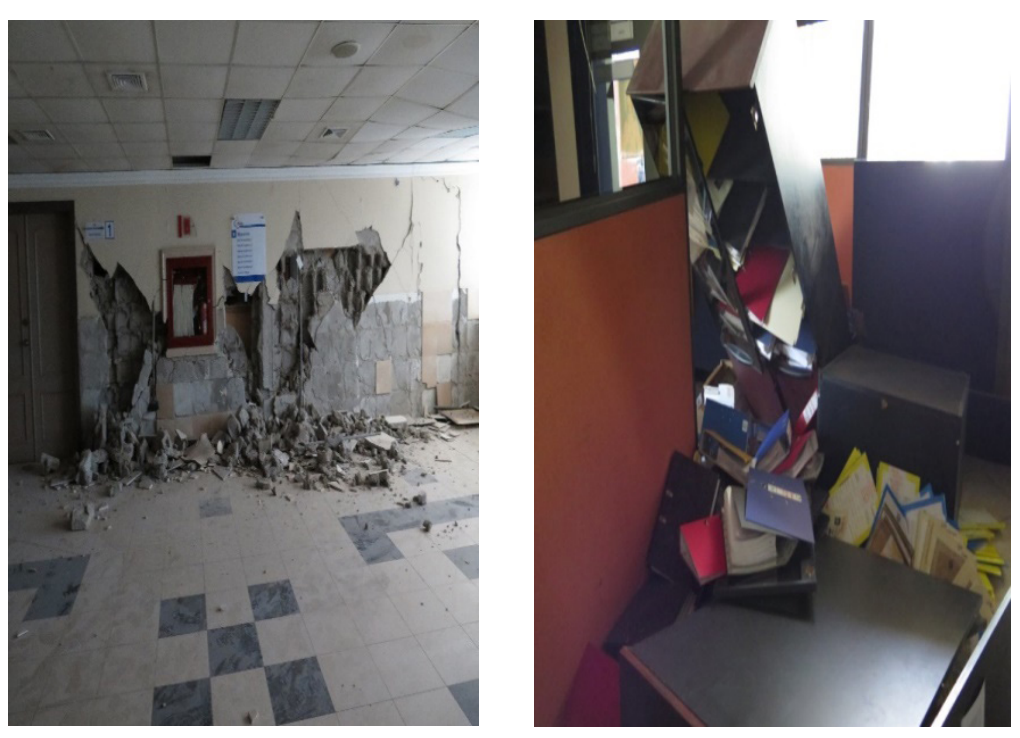

Figura 1. Daño en mamposterías y elementos no estructurales 


\section{SISMOS RECIENTES Y EFECTO SOBRE LAS CONSTRUCCIONES}

Ya el sismo de 1998 de Bahía de Caráquez puso en evidencia defectos tales como estructuras aporticadas excesivamente flexibles y mamposterías pesadas y frágiles que sufrían mucho daño. Los mejores ingenieros estructurales de nuestro país enfrentaron el reforzamiento de las edificaciones dañadas mediante encamisados importantes no tan solo de las columnas sino de las vigas y con el empleo de mejores materiales y mano de obra para las mamposterías. Se logró, en efecto, reducir notablemente los desplazamientos horizontales de las estructuras y por tanto se pensó que también los daños en las mamposterías. Sin embargo, el sismo de 16 de abril de 2016, volvió a producir los mismos daños ya observados en el sismo de Bahía y en los mismos sitios. La conclusión a la que se llega es que no hay forma, a costos razonables, de que las estructuras aporticadas tradicionales se comporten adecuadamente ante las cargas sísmicas. Es necesario generar nuevos patrones de construcción con elementos relativamente nuevos en nuestro medio.

\section{ALTERNATIVAS: MUROS ESTRUCTURALES Y SISTEMAS DE AISLACIÓN SÍSMICA}

Una primera alternativa para reducir daños son los muros estructurales como complemento de los pórticos.

Pero usar muros implica ubicarlos adecuadamente para evitar torsión en planta, es decir hacia el centro de las plantas de las edificaciones. Implica que para reducir costos, se construyan pórticos sismorresistentes sólo en el perímetro de dichas plantas, y que por tanto las cargas verticales hacia el interior sean absorbidas por columnas conectadas directamente a las losas de piso. Implica también que estas losas deben funcionar como diafragmas y que por tanto necesitan ser macizas. Es decir se trata de un cambio radical con la forma tradicional de construcción mediante sistemas aporticados. La Figura 2 ilustra algunas de las ideas anteriores con un gráfico obtenido del código norteamericano $\mathrm{ACl} 318 \mathrm{~S}-14$

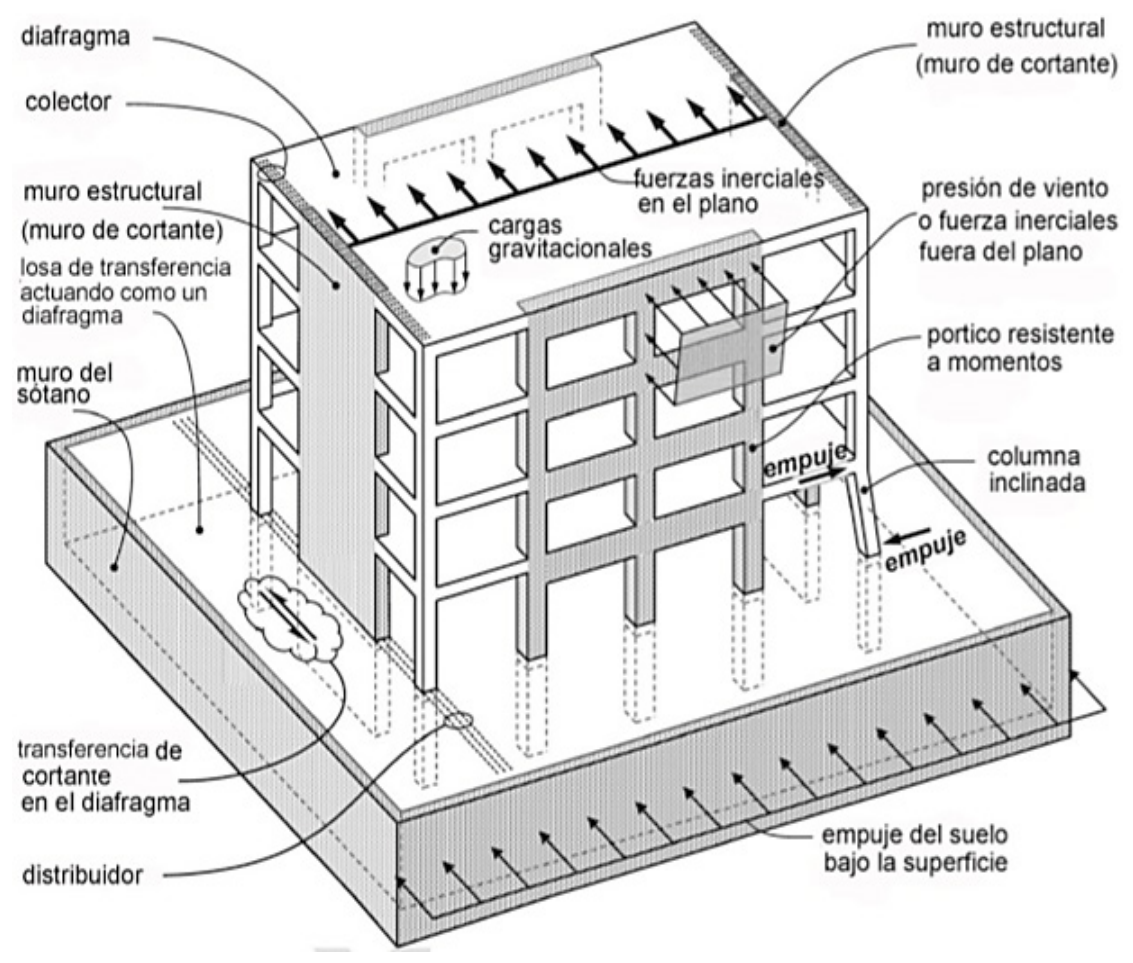

Figura 2. Edificaciones sismorresistentes (Fuente: ACI 318S-14)
Pero no tan sólo esto, vale la pena cuestionarse ¿̇por qué enfrentar al sismo aceptando daño aunque sea controlado? ¿Por qué no, de la misma forma que un torero hace el quite a un toro, hacerlo pasar 
sin que dañe una estructura? En efecto ya existe la tecnología, por medio de aisladores sísmicos, que absorben el impacto sísmico, evitan grandes deformaciones y por tanto daño.

Afortunadamente, la Universidad de las Fuerzas Armadas ESPE está usando esta tecnología en su Nuevo Centro de Investigaciones Científicas. Debajo de cada una de las columnas de la estructura metálica se ha colocado un aislador de triple péndulo cuyas dimensiones se indican en la Figura 3.

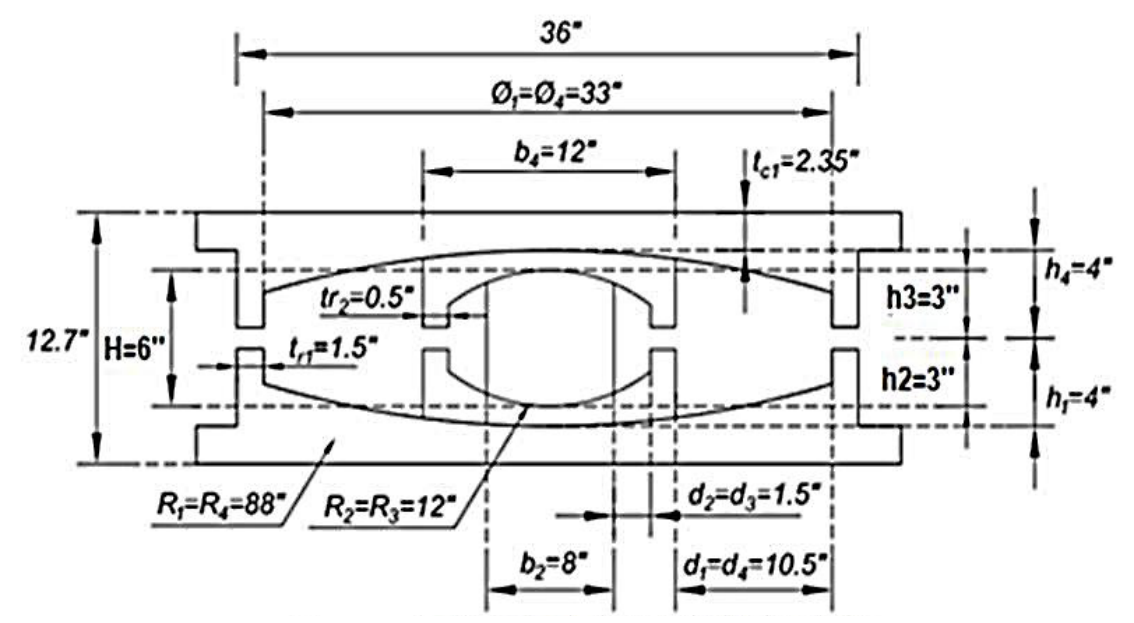

Figura 3. Geometría del aislador de triple péndulo

Este tipo de aislador resiste las cargas laterales por fricción, pero cuando estas se superan, su cuerpo interior se desplaza y se ve obligado a subir por una superficie cóncava, por lo que el mismo peso de la estructura lo empuja de nuevo a la posición inicial. Lo importante es que las deformaciones en la estructura son relativamente pequeñas y como ya se ha indicado el daño es relativamente leve. La Figura 4 muestra un aislador colocado ya bajo una columna metálica y una vista del avance de la construcción.
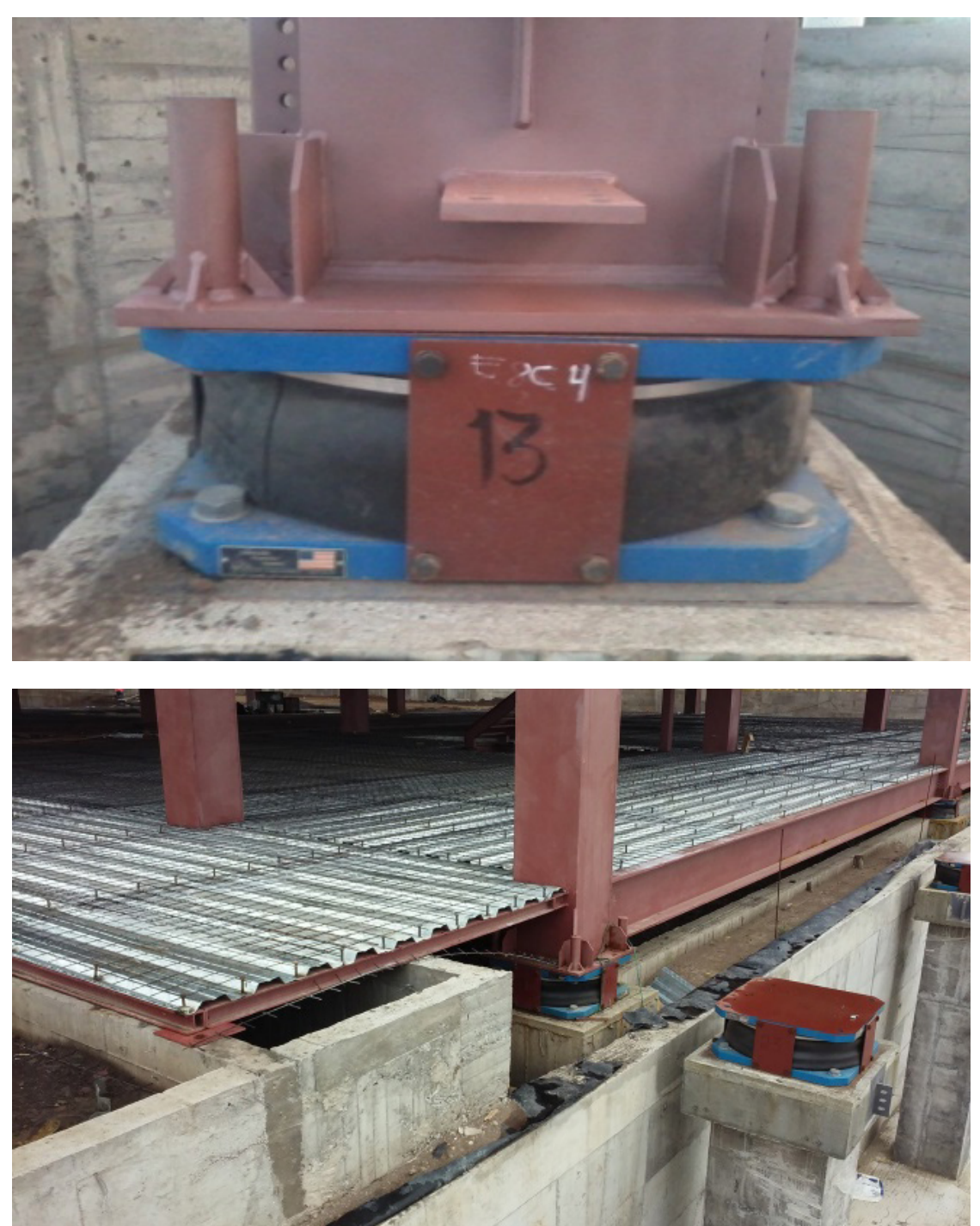

Figura 4. Aisladores sísmicos en el Nuevo Centro de Investigaciones Científicas ESPE 


\section{CONCLUSIONES}

El sismo de 16 de abril de 2016 ha mostrado la necesidad de cambiar los sistemas constructivos tradicionales. Pero las alternativas ya existen y en este artículo se han indicado dos: sistemas duales, es decir pórticos complementados con muros y, sistemas de aislamiento sísmico tales como los de triple péndulo.

Para finalizar, ટ̇cómo lograr que este sistema constructivo se generalice? Un papel fundamental lo cumple la enseñanza en los cursos regulares de ingeniería civil de las características de este sistema, pues posteriormente los nuevos ingenieros lo difundirán en sus empresas y trabajos.

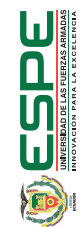

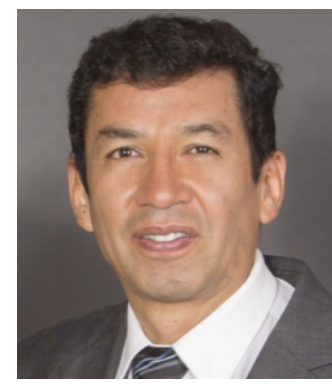

\section{PABLO CAIZA SANCHEZ}

Obtuvo su PhD en Ingeniería Civil en la Universidad de Illinois en UrbanaChampaign en el año 2012. Allí fue primero becario Fulbright y luego Asistente de Investigación, siendo además Asistente de Docencia en varios cursos de estructuras. Tomó asignaturas tales como Hormigón Armado II, Estructuras de Acero II, Hormigón Presforzado, Métodos con Elementos Finitos, Mecánica Estructural, Dinámica Estructural, Ingeniería Sísmica, Análisis de Riesgos y Toma de Decisiones, Cimentaciones Profundas, Optimización Estructural, Hormigón, Madera, Acero.

Previamente obtuvo su M.Sc. en Estructuras en la Escuela Politécnica Nacional de Quito, y fue el mejor graduado de Ingeniería Civil en la Escuela Politécnica del Ejército (ESPE).

También realizó cursos de posgrado en la Middle Tennessee State University en los Estados Unidos de Norteamérica, y en la Fachhochschule Hildesheim-Holzminden en Alemania.

Sus principales temas de investigación son: el análisis y diseño de estructuras con diferentes sistemas resistentes a cargas sísmicas, comportamiento no lineal de estructuras, monitoreo estructural, sistemas de aislamiento y de disipación de energía, interacción suelo-estructura considerando fenómenos tales como licuefacción y radiación de energía a través del suelo.

Actualmente trabaja en la Universidad de las Fuerzas Armadas ESPE. 